Januario Espinosa.

\title{
INUTILIDAD DE LA ACTUAL ACADEMIA ESPAÑNOLA
}

- USCABA yo un día, en el mejor diccionario (D)) inglés-español, la traducción de la expresión spring-clean que aparecía en una revista londinense, y como no encontrara este compuesto junto al vocablo spring ni tampoco junto a clean, ni menos atinara a establecer su significado por simple dedución, recurrí a un compañero de oficina que sabe, o cree saber, mucho más inglés que yo. Pero igualmente se dió por vencido.

-No - acabó por decir - ; será inútil que busquemos. Con la facilidad que tienen los ingleses para formar compuestos, nace en los países anglo-sajones una expresión nueva cada día. Esto aparte de las que se forman por extensión.... Aquí mismo tenemos el ejemplo con la palabra patilla, de uso ya general en el sentido de engaño, farsa, mentira y más especialmente de algo que ponga a prueba nuestra paciencia. Supóngase usted a un extranjero que crea saber muy bien el español, y se encuentra con este vocablo en algún libro o puAtenea. -35 
blicación chilenos. Será inútil que consulte los diccionarios para establecer su significado. El último de la Academia le dará tres acepciones de patilla: una parte de la guitarra, otra parte de una arma de fuego, y el diablo, si va en plural. Si busca más, en las enciclopedias, verá que también se llama patillas "a los pelos que se deja crecer debajo de las sienes». Si el extranjero este es un alemán, armado, por lo tanto, de mucha paciencia, y dotado de mucha curiosidad científica, se proveerá de algún diccionario de chilenismos, con lo que logrará establecer que las tres acepciones que da a patilla la Academia son absolutamente desconocidas en Chile, y, en cambio, tiene la única que en España desconocen: "los pelos que crecen en la parte inferior de la cara», lo que se llama barba, según los diccionarios de la lengua. Con todo esto, el alemán seguirá siempre a oscuras, y no le quedará más remedio que buscar a un chileno o irse donde el cónsul. Así comprobará una vez más que los idiomas, en su constante evolución, van dando a las palabras acepciones que no tienen ninguna relación con su origen. Patilla, ya se sabe, deriva de pata, y. pata, según los diccionarios, viene del sanscrito padas, "pie».

Las palabras de mi amigo me dejaron un tanto confuso.... Entonces, ¿para qué sirve un diccionario? Pero después de ligera reflexión, convine en que era natural que patilla no figurara en el léxico con la acepción chilena de farsa, engaño, etc., por ser de formación reciente; pero que otras palabras usadas por todas las personas en Chile, desde hace muchos años, y a través de todo el país, como chupalla, futre, chaucha, fuñingue, etc., estarían con toda seguridad en la última edición del Diccionario de la Academia (1925). Grande fué mi decepción al no encontrar éstas, ni otras que tomé al azar entre las más corrientes.

Especialmente me causó espanto que la Academia no tenga noticias, por ejemplo, de la existencia del vo- 
cablo chaucha, que tiene un uso ya viejo y muy extendido en varios países de la América española, eso sí que con acepciones diferentes: moneda en Chile y Bolivia, los porotos verdes en Argentina, un autobús en Cuba, etc.

Es verdad que muchas palabras de gran difusión en América y que no han sido tomadas en cuenta por los académicos, son incluidas en las enciclopedias; pero las explicaciones que éstas dan suelen resultar disparatadas. Así la más completa y reciente enciclopedia española, la de Espasa, de la siguiente definición de chupalla:

Chile. Planta cuyo nombre científico es Paya pyramidata. Chile. Sombrero que se hace de las hojas de esta planta, partidas en tiritas muy finas y trenzadas unas con otras. fig. $y$ despect. Cualquier sombrero de paja cuando ésta no es muy fina.

Como se ve, la tercera definición es acertada: sólo que chupalla no pertenece al lenguaje figurado ni tampoco al despectivo. En cuanto a las dos primeras..., ¿quién conoce en Chile la planta que lleva ese nombre, y a quién se le ha ocurrido alguna vez llamar así al sombrero de pita o al jipijapa? Y por último, ya sabemos que no a cualquier sombrero de paja se le llama chupalla en Chile, pues a la condición de ser hecho de paja ordinaria debe reunir la de tener el ala ancha y flexible.

De chuchoca, que tampoco figura en el Diccionario de la Academia, dice lo siguiente la Enciclopedia Espasa:

Amer. Maíz tostado y molido que se emplea como aditamento de muchos guisos.

Pues bien, todos sabemos que a esto se le llama por acá «harina de maíz tostado", que el maíz molido en 
crudo es simplemente sharina de maíz" y que la chuchoca es harina de maíz sancochado. La misma Enciclopedia dice que charol es en Chile, Cuba y Ecuador sel nombre de una bandeja de hojalata, pintada y barnizada». Igualmente asegura que en Chile llamamos "chupón» a la pieza de marfil, pasta, caucho, etc., que se les pasa a los niños en la época de la primera dentición.

Ocurre también que muchas palabras que son por acá de uso corriente, aparecen en el léxico oficial, pero sólo con la acepción que le dan en la península. Tal ocurre con catre. «Cama pequeña, portátil» dice simplemente la Academia; de manera que un extranjero que llegue a Chile y vea en los diarios grandes avisos en que se ofrece «catres de bronce» por sumas de cuatrocientos o quinientos pesos, pensará inmediatamente que los chilenos somos sumamente lujosos, cuando gastamos tanto en un simple lecho de campaña.

Un distinguido general en retiro, muy aficionado a estas "cuestiones de voquibles», proponía el otro día en un diario que sólo se usara la palabra catre en el sentido que le da el Diccionario. ¿Y por qué razón cuatro millones de chilenos nos hemos de someter a la voluntad de cuarenta caballeros ancianos, que conocen la América española sólo en el mapa? Con toda justicia afirma De Saussure que en estas cuestiones de lenguaje el único soberano es la masa parlante, que entierra unos vocablos para siempre, y a cada instante está creando nuevos. Muchos de estos recién nacidos no prosperan, pero los más vigorosos, tonificados por la necesidad, o por simple buena suerte, concluyen por imponerse, pese a todos los académicos y puristas.

Igual que con catre ha pasado en la Academia con el verbo pitar. «Tocar el pito» lo define solamente. No sospecha que en Chile el pueblo lo usa en sustitución de fumar. Pitanza es "comida» conforme al Diccionario, pero esto es griego para los chilenos. Puede soste- 
ner el léxico lo que le parezca, pero aquí pitanza será siempre "una burla ligera» y pitar, además de *fumar», tendrá la otra acepción de «burlar», usado como reflejo.

Muchos pensarán que estas omisiones, o malas definiciones del Diccionario, no tienen mucha importancia, ni a nadie causan perjuicio. Profundo error, y voy a citar un caso. La más grosera expresión chilena, muy usada por la gente baja, y empleada también como interjección en ciertas ocasiones, aun por gentes de la clase alta, figura en el Diccionario de la Academia, pero sólo con el significado que le dan en España: $" \mathrm{Pe}-$ rra». Aparenta ignorar la Academia que la misma palabra es en Colombia el nombre de un animal que causa perjuicios en las casas; que en México es el diminutivo cariñoso de un nombre de mujer, de María Jesús o Jesusa, y que en Chile tiene un significado obsceno. Un extranjero que llegue a Chile y oiga la dicha palabrita, como el Diccionario no lo previene, se expone a usarla entre señoras, con el consiguiente escándalo. Un oficial que fué en la Baquedano en la gira que hizo hace dos o tres años por los países de Hispano-América, me refería que en la ciudad de México figura esta palabra como nombre de una pastelería, lo que dió lugar para que todos los oficiales y la tripulación, desfilara por esa calle, sólo por ver el famoso letrerito. ¿Por qué no podría presentarse el caso que algún mexicano recién llegado a Chile gratifique con esa expresión a una señorita que se llame María Jesús?

No hace mucho (la noticia me la dió un profesor de castellano), un español recientemente llegado a Chile usaba continuamente, para llamar a una perrita, la horrible palabra, con gran espanto de las vecinas; pero ninguna se atrevía a sacarlo de su error. Lo hizo, al fin, un hombre de buena voluntad. Parece que el mismo vocablo no tiene en España el único significado que la Academia consigna: pues ocurrió el caso que una señora andaluza lo llegó usando a Valparaíso en reem- 
plazo de "calor». Dicen que la Academia tiene por principio no incluir en el Diccionario ningún vocablo obsceno. ¡Cuánta sería la vergüenza de estos graves caballeros si vinieran a Chile y se pusieran en contacto con el pueblo! Verían que, como el personaje de Molière, habían estado hablando en prosa sin saberlo.

Algo parecido nos ocurre con un verbo que es usado en Argentina, tanto por el pueblo, como por la gente «bien» en el sentido de nuestro "pololear» o flirtear. Ese verbo tiene en Chile un significado que sólo puede ser usado entre hombres. Uno de los cadetes que vinieron de Buenos Aires después de la catástrofe de Alpatacal, me dijo que allá les habían advertido que no fueran a caer en el renuncio de usar esa palabra en Chile, porque harían una gran plancha. Pero hay argentinos que vienen sin esta previa advertencia, y no libran de ponerse en ridículo. Se dan muchos casos.

Un amigo colombiano me previno en una ocasión que si un día iba a su país, me guardara, en caso de asistir a un baile, de decir a mi compañera de danza "disculpe que la haya pisado", porque me haría reo de una gran grosería.

El propio nombre de nuestro país, además de ser aplicado al ají en México, tiene allí también un significado inconveniente. En un banquete en la ciudad de México, un Ministro chileno pronunció hace años esta frase que provocó risas veladas y comentarios posteriores: «En adelante podremos decir: ¡México para los chilenos y Chile para los mexicanos!»

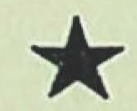

En los anteriores casos se indican solamente las palabras que siendo cultas en un país de la familia hispana, pasan a ser groseras en otro. En realidad, el nú- 
mero de vocablos que tienen diferente acepción entre los pueblos que hablan español es muy grande, y seguramente son minoría los que figuran en el Diccionario oficial con todas sus acepciones en América. Luego, como, por otra parte, el mismo Diccionario no ha incluido muchas palabras de gran uso por acá y con muchos años de existencia, y de otras da indicaciones equivocadas o insuficientes, no nos resulta muy útil para nosotros los hispano-americanos. Figuran en él, en cambio, centenares de palabras que ya no usa nadie, con lo que se va convirtiendo en un cementerio de vocablos. Ocurre, en realidad, que la Academia va en la vieja carreta con bueyes, mientras el idioma evoluciona en tren expreso. Los puristas se detienen a la orilla de la línea para lanzar imprecaciones al tren, en la esperanza de detenerlo; pero el tren sigue avanzando, porque el idioma es una cosa viva: ini mil Academias lograrán nunca congelarlo!

La causa principal de estos vacíos del Diccionario, de su gran atraso, sobre todo en lo que se refiere a América, está en la formación misma de la Real Academia Española. Los cuarenta escritores, magnates y militares que la componen, se reunen especialmente para «fijar, limpiar y dar esplendor» al idioma; pero ocurre que estos caballeros sabrán mucho sobre el lenguaje que se habla en Madrid o en las provincias españolas donde nacieron y crecieron; pero todo lo ignoran del resto de los países donde se habla la lengua de Cervantes. Es verdad que se han creado Academias correspondientes en el resto de los países que hablan español, pero estas Academias locales o no se constituyen, o se reunen muy poco. En todo caso, lo que hagan ha de pasar después por el tamiz de la Academia principal, con lo cual los años corren....

Lo único racional, y que salta a la vista, sería que la Real Academia Española estuviera formada por representantes de todos los países de habla española. 
En el sentido político, España es una nación independiente; pero desde el punto de vista del idioma castellano no es sino una provincia de esta vasta nación que comienza en los Pirineos y termina en el Cabo de Hornos. ¿Con qué derecho esa provincia, aunque por ahora sea la más poblada, se arroga la facultad de imponer su ley a las diecinueve provincias restantes? ¿Qué fuerza tiene para pretender que hablemos como se habla en la península?

Se ha mirado hasta aquí la Academia como un lugar de consagración de los grandes escritores. Como hasta ahora no ha ingresado a la ilustre corporación ningún americano, se podría creer que sólo España produce escritores de valía. Otra injusticia grande. Naturalmente que en su calidad de nación madre, España tiene derecho a ser la sede perpetua de esta Academia; derecho tiene también, por su población y por la indicada circunstancia, a tener mayor número de representantes; pero de ahí a adjudicarse todos los derechos, y a seguir mirándonos como simples colonos, desde el punto de vista del idioma, hay gran distancia. Mientras esta situación absurda no se arregle, el Diccionario que la Academia publica será cada vez más inútil; porque cada día será mayor la diferencia entre el lenguaje hablado en la América hispana y el aceptado oficialmente por la Ilustre Corporación madrileña.

El cable dió cuenta de las gestiones de don Julio Vicuña Cifuentes en Madrid, para que se celebre un Congreso del Idioma. Ya este sería un paso firme en el verdadero sendero. Sólo que un Congreso de esta naturaleza, por ser temporal, sólo produciría bienes temporales. Después volveríamos a la misma anarquía. Preferible sería ir francamente a la única solución lógica: la de disolver la actual Academia, para sustituirla por otra más real (de acuerdo con la realidad de las cosas) y más Española (en el sentido de la lengua). Y de esta Academia podría salir un Diccionario del 
idioma vivo, del que se está hablando en las veinte naciones nacidas del tronco de Castilla, Diccionario que reemplazaría al actual cementerio de vocablos. ¿Que es necesario registrar las viejas voces, para poder entender a los clásicos? Publíquese entonces, en tomo aparte, un Diccionario de arcaísmos.

¿Quiénes irían a esta nueva Academia como representantes de los países hispano-parlantes de América? Muchos pensarán en los filólogos. Pero sería preferible enviar escritores de mérito, y con suficiente experiencia. El escritor usa constantemente el idioma, lo pulsa, lo baraja, está más en contacto con las palabras nuevas, con su verdadero espíritu. En todo caso, mira estas cosas con un criterio más liberal, más amplio. Los filólogos, llenos de tecnicismos, apegados a las reglas, son más conservadores. Menos aun servirían los que han adoptado la profesión de "puristas.» Son los que se empeñan en que llamemos "fogonero» o "piloto* al chofer, que en vez de "góndola» digamos «jardinera» y «tío vivo» en lugar de carrusel.

\section{实}

Terminado este artículo, me asalta una duda: ¿con qué derecho me pongo yo a opinar sobre estas cosas? Quédese para los filólogos, para los profesores de castellano. Ya enuna oca sión, por haber transcritolas afirmaciones de un conocido lingüista ginebrino, y haber avanzado otras, basadas en mis lecturas, provoqué la indignación o poco menos de dos o tres especialistas. Se me señalaron errores, según ellos muy graves. Y yo hube de replicar, en mi defensa, que si los lingüistas, que saben mucho, se equivocan constantemente en estas materias, ¿cómo no he de equivocarme yo, que en asuntos lingüísticos estoy en el silabario? 
Lo natural es que no opine.... Pero me he decidido, porque abrigo la esperanza de que, guardadas las debidas proporciones, me ocurra lo que a José María de Heredia, el gran poeta francés. La anécdota la refería así Albert Cim en el número de 15 de mayo de 1924, de La Revue Mondiale:

La palabra haricot es uno de los vocablos cuya etimología ha sido, durante largo tiempo, de las más oscuras y de las más discutidas; $y$ parece que sólo recientemente se han puesto de acuerdo sobre el origen de ese término. Es a un poeta, José María de Heredia, a quien se debe la clave de este enigma, y el mismo refirió jocosamente el incidente, en el número de Navidad de 1901, de los Annales politiques et littéraires.

Una dama interrogaba un día a Heredia sobre su célebre libro Les Throphées, y le pedía que le indicara cuál de sus sonetos prefería. No queriendo en absoluto pronunciarse, el poeta dió a aquella dama esta curiosa respuesta:

- Hay una cosa de la que yo estoy más orgulloso que de todos mis sonetos, y que ha hecho más por mi gloria que mis versos.

\section{- ¿Cuál?}

Heredia contó entonces que él había encontrado referencias sobre los «haricots" buscando ciertos datos en un libro de historia natural del siglo XVI por Hernández, De historia plantarum novi orbis. La palabra haricot era desconocida en Francia hasta el siglo XVII, continuó; se decía fèves o phaséots; en mejicano ayacot. Treinta especies de frejoles (haricots) eran cultivados en Méjico antes de la conquista. Se les nombra hasta la fecha ayacot, sobre todo el frejol rojo, punteado de negro o de violeta. Un día me encontré en casa de Gaston

Paris con un gran sabio. Al oír mi nombre, avanzó hacia mí y me preguntó si era yo quien había descubierto la etimología de la palabra haricot. Ignoraba absolutamente que yo hubiese hecho versos y publicado Los Trofeos. 